\title{
Effect of Ni and Cu Substitution on the Crystal Structure, Morphology and Electrochemical Performance of Spinel $\mathrm{LiMn}_{2} \mathrm{O}_{4}$
}

\author{
Azhar Iqbal ${ }^{1, *}$, Abdul Majeed Khan ${ }^{2, *}$, Tao Wang ${ }^{1}$, Daocong Li $^{1}$, Yuxian Gao ${ }^{1}$ \\ ${ }^{1}$ Institute of Engineering Research, Hefei Guoxuan High-Tech Power Energy Co., Ltd, Hefei, 230011, \\ P. R. China. \\ ${ }^{2}$ General Studies Department, Jubail Industrial College, Jubail Industrial City 31961, Kingdom of \\ Saudi Arabia. \\ *E-mail: aiqbalchemist@yahoo.com, fahmigul@yahoo.com
}

doi: $10.20964 / 2019.01 .79$

Received: 24 September 2018 / Accepted: 28 October 2018 / Published: 30 November 2018

\begin{abstract}
$\mathrm{Ni}$ and $\mathrm{Cu}$ bi-metal doping of spinel $\mathrm{LiMn}_{2} \mathrm{O}_{4}$ materials are investigated by characterizing the as prepared materials by XRD, FTIR, SEM, TEM, CV, Charge/discharge measurements and electrochemial impedance spectroscopy (EIS). Although, $\mathrm{Ni}$ and $\mathrm{Cu}$ doping decreased the initial discharge capacity, the optimized composition such as $\mathrm{LiNi}_{0.01} \mathrm{Cu}_{0.01} \mathrm{Mn}_{1.98} \mathrm{O}_{4}$ demonstrates good capacity retention after prolonged charge/ discharge cycling and high rate capability. The observed enhanced electrochemical performance of Ni-Cu bi-metal doped samples may be attributed to the suppression of the strucutral changes along with improved lithium-ion kinetics during charge/ discharge process.
\end{abstract}

Keywords: Electrochemical performance; Metalsdoped Li-Ion Batteries;

\section{FULL TEXT}

(C) 2019 The Authors. Published by ESG (www.electrochemsci.org). This article is an open access article distributed under the terms and conditions of the Creative Commons Attribution license (http://creativecommons.org/licenses/by/4.0/). 